\title{
Embracing the Selfie Craze: Exploring the Possible Use of Instagram as a Language mLearning Tool
}

\author{
Sebah Al-Ali \\ Higher Colleges of Technology, Sharjah, UAE
}

\begin{abstract}
Although only introduced in October 2010, Instagram has quickly gained popularity and become one of the popular social media tools used around the world. This paper reports an action research attempt to integrate Instagram as an active mLearning tool in a language bridge program. Instagram was used as a production tool for a holiday project and two writing activities in two preintermediate/intermediate ESL classes. Results of the study suggest that although students were not enthusiastic with the initiative at first, they gradually welcomed the idea and were encouraged to be creative in completing their writing activities. A few teaching implications were concluded from this experiment for a better integration of Instagram as a learning tool in language classrooms.
\end{abstract}

Keywords: Instagram, language learning, social media, mLearning, SAMR model

Social media is a term used to refer to a set of Web 2.0 e-platforms used to "socialize, gossip, share information, and hang out" (Boyd, 2014, p. 6) with other platform users, on different levels. Examples of these platforms include, Facebook, Twitter, Instagram, and Linkedln. These platforms are heavily accessed by younger generations (Counts \& Fisher, 2010; Dunn, 2013; Lunden, 2014; Oliveira, 2014). Although most social media outlets have a Web version, they are heavily accessed via mobile technologies: smart phones and tablets (Global Digital Statistics, 2014).

Since its introduction, social media have been integrated in classrooms and implemented for learning purposes in various ways (Gikas \& Grant, 2013; Mao, 2014). In fact, Seaman and Tinti-Kane (2013) report in their survey that there is an increase in using social media tools in classrooms with a majority identifying blogs and wikis as their main social media learning tool. Probably due to its recent introduction to the field, Instagram hasn't received much research attention in terms of what it can offer in the learning/teaching process.

\section{What is Instagram?}

Instagram is a social media tool introduced in 2010. It is used to share photos, and starting from mid-2013 Instagram's services expanded to sharing 15-second videos (Press Page, n.d.). It is one of the few social media tools originally designed for mobile use through apps. Using a mobile app, an Instagram user can perform a number of functions: create accounts, post content (pictures or 15-second videos), apply filters, add captions, tag users, add locations, add hashtags, like content, add comments, 
browse and follow other accounts, check a feed generated by followed accounts, and explore (search for) hashtags/users. Instagram's web version, however, has very limited capabilities and can be used for limited viewing purposes only (see Table 1). Unlike other social media tools, Instagram is mainly based on the idea of posting one's own content. Re-sharing functions are not readily available; there is no re-share function in the official app, and users cannot legally save others' pictures.

Table 1. Availability of Instagram functions via its mobile apps compared to its website

\begin{tabular}{lll} 
Functions & Mobile Apps & Website \\
\hline Create accounts & Available & Unavailable \\
Post content & Available & Unavailable \\
Apply filters & Available & Unavailable \\
Add captions & Available & Unavailable \\
Tag users & Available & Unavailable \\
Add locations & Available & Unavailable \\
Add hashtags & Available & Unavailable \\
Like content & Available & Available \\
Add comments & Available & Available \\
Check feed & Available & Available \\
Browse and explore hashtags & Available & Unavailable \\
Browse and follow accounts & Available & Available
\end{tabular}

\section{How Popular is Instagram?}

Instagram's popularity around the world can be seen through its statistics. As shared on Instagram's website, in two months after its launch, Instagram reached a million users, and in less than a year, 150 million photographs were uploaded to Instagram. It currently has 200 million active users; a bank of 20 billion photographs with an average of 60 million photos a day and an average of 1.6 billion likes a day (Press Page, n.d.). Lunden (2014) also reported that while Facebook is the most commonly used social media platform around the world, Instagram is gaining popularity the quickest. This could be partially attributed to the fact that many famous figures around the world have active accounts on Instagram and post regular updates, like Barack Obama (@barackobama), Hamdan bin Mohammed (@faz3), Cristiano Ronaldo (@cristiano), and Oprah Winfrey (@oprah). In addition to this popular trend, Mao's (2014) report of students' attitudes and usage of social media ranked sharing pictures and videos as one of the top three most common usages of social media, one of Instagram's basic functions.

\section{Instagram in Language Classrooms}

There have been multiple studies and research papers investigating the use of various social media platforms like Facebook (e.g., Bowman \& Akcaoglu, 2014; McCarthy, 2010) and Twitter (e.g., Krüger-Ross, Waters, \& Farewell, 2012; Reed, 2013; Warren \& Wakefield, 2012) in classrooms. Very few if any, however, discuss the use of Instagram in education, or in language classrooms. Bell (2013) reported her attempts at using Instagram for 
college students' field trips in a library science course. Salomon (2013) and Tekulve \& Kelly (2013) also discussed their institutions' libraries' successful experience in using Instagram to reach their young audience as compared to other social media tools.

Although Instagram has limited functions, it can be useful in language classrooms. Instagram offers a plethora of contextualized visual data that can provide aid in language classrooms. These aids are especially useful because they offer visual elements that can cater to visual learners. Also, using Instagram in classrooms can assist in creating a socially connected community of learners, as the tool itself gives room for students to communicate and socialize with each other beyond classroom constraints. Socializing on Instagram is mainly done through the like and comment functions, which are not taken for granted by Instagram users.

Another important rationale behind this paper's call for actively utilizing Instagram as a language learning tool is that Instagram is a commonly used social media outlet that young learners are now almost fully immersed in and accustomed to; including it in their learning process can be seen as a form of applying topics learned in class in real life environments (Vie, 2008). Also, young learners' familiarity with Instagram can be seen as an advantage as it can lessen possible stress caused by integrating unfamiliar tools into learning activities (McBride, 2009). Finally and most importantly, ease of access to Instagram and availability in most handheld devices makes it more inviting to consider this platform for use in language classrooms.

\section{Instagram and SAMR}

SAMR is a theoretical framework that explains the various degrees of technology integration in classrooms (Puentedura, 2009). As illustrated in Figure 1, the framework outlines four levels of integration starting with basic substitution where technology is used to replicate existing modes of instruction and ending with a redefinition stage where learners are actively shaping their learning experience in ways that can only be done using technology.

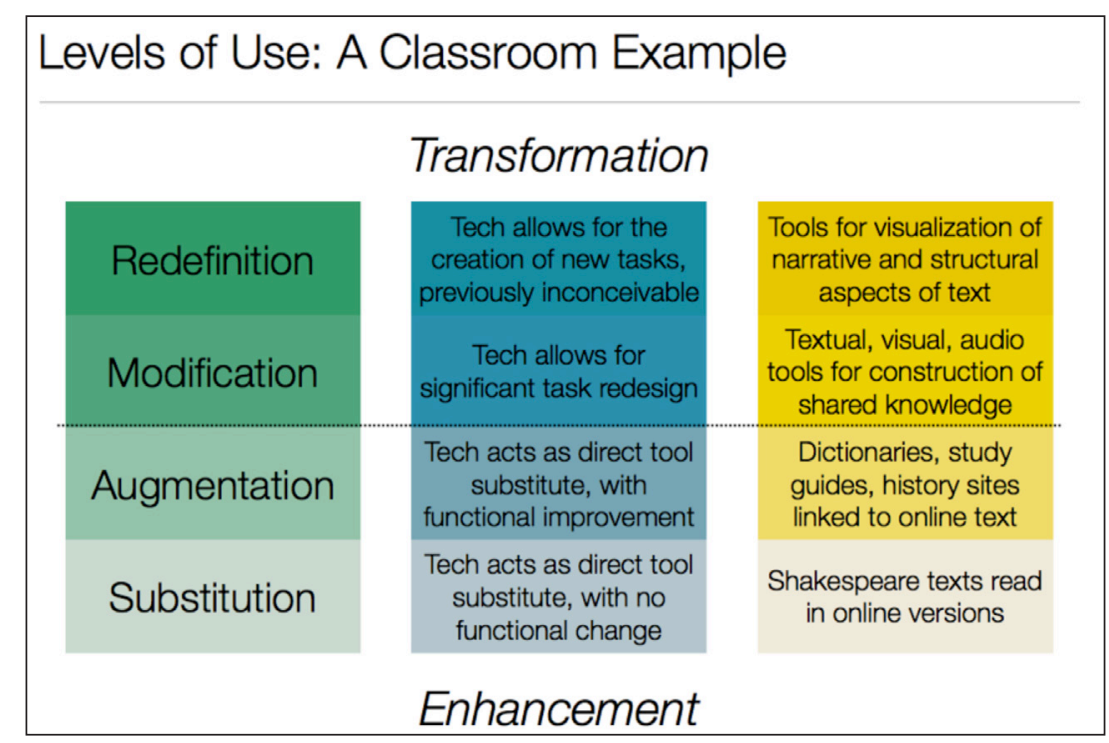

Figure 1: The SAMR model as explained by Puentedura (2009) 
In other words, according to this framework, the best utilization of an e-tool in classrooms occurs when a tool facilitates active student involvement in the learning process. This kind of active involvement is important in the language classroom as it makes learning a language more effective, as noted by Hockly (2012).

A number of studies evaluated the use of different e-tools using this model. Cavanaugh, Hargis, Kamali, and Soto (2013) examined submissions made to two educationaltechnology conferences in which teachers explained their ways to implement iPads as learning tools in their classrooms. Upon examining data using the SAMR scale, they found that teachers' tendency to reach modification and redefinition levels of technology implementation increased as they gained more experience with iPads in classrooms. Chell and Dowling (2013) also highlight a few iPad apps that were used by teachers at a language bridge program and ranked them according to the model. It was noteworthy that the level of integration was not app-specific. A few apps were used by some teachers as substitutes for current modes of instruction while being used at the same time to redefine learning by other instructors. One of these apps was Keynote, a presentation tool for iPads. When used as a substitute for older teaching modes, Keynote was used by teachers to replicate what they used to do without technology: present information to their students. On the other hand, Keynote allowed more experienced teachers to provide students with active learning opportunities in which students were asked to create and present a presentation (or a movie using iMovie) to show their understanding of vocabulary items covered in class. Chell and Dowling explain that with such a learning experience, "students became content creators and facilitators, presenting information to their peers for learning purposes." (p. 26)

As mentioned previously, although limited research is reported in the literature in regards to utilizing Instagram in educational settings, Instagram can facilitate a redefinition of language classrooms, as defined in the SAMR model, by allowing students to create videos or take pictures to address their learning objectives. The action research reported in this study aimed to see how easily Instagram can be implemented in a language classroom setting to facilitate active learning, or as defined by SAMR, a redefinition stage.

\section{Research Design}

\section{Context and Participants}

The Middle Eastern higher education institution in which this study took place adopts a positive attitude towards integrating technology in classrooms and encourages/supports it by a variety of methods. This project was implemented in two classrooms of the same level and content with around 20 female students in each. The participants' age group ranged from 17 to 21 years old. They were in their first semester of a bridge program that offers intensive English lessons to enhance their language skills. Their proficiency levels ranged from pre-intermediate to intermediate. All of them had access to either a tablet or a smart phone and a Wi-Fi connection in every class. 


\section{Data Collection and Analysis}

The main aim of this project was to see how seamlessly Instagram can be integrated as a mLearning tool without negatively affecting the flow of classes or students' learning preferences. This explains why while activities were generally planned before going into class, each activity was modified on the run in response to students' feedback and preferences. The teacher assigned activities and noted her observations in a reflection journal. She also continuously asked for students' feedback to measure their satisfaction levels with tasks and with the use of Instagram as part of their learning process. Their feedback was instrumental throughout the project as it helped restructure activities to better suit their preferences and needs.

Samples from students' work for activities two and three were later taken from BlackBoard Learn, the learning management system at the institution. Samples for the first activity were not documented or kept because of the nature of the activity. Discussion of results and implications was reached based on the teacher's feedback and journal entries, and ongoing feedback received from students throughout the experiment. A short anonymous survey was also given to students towards the end of the semester to measure their satisfaction in general with using Instagram as a language mLearning tool. 16 students voluntarily filled it out.

\section{Findings}

As dictated by the previously assigned learning outcomes for this level/semester, the teacher managed to integrate Instagram as an mLearning tool for 3 language in-class activities targeting speaking, writing, grammar and vocabulary skills. Table 2 summarizes the three activities and the learning tasks involved in each one.

Table 2. Instagram was used as an mLearning tool for three language learning activities

\begin{tabular}{|c|c|c|c|}
\hline Activity - Type & $\begin{array}{l}\text { Language } \\
\text { Skills }\end{array}$ & Learning Tools & Learning Tasks \\
\hline \multirow{2}{*}{$\begin{array}{l}\text { Activity } 1 \text { - } \\
\text { Individual work }\end{array}$} & Speaking skills & Instagram & Take/post 10 pictures to Instagram \\
\hline & $\begin{array}{l}\text { Vocabulary } \\
\text { skills }\end{array}$ & Keynote & $\begin{array}{l}\text { Create/present a presentation using } 5 \\
\text { pictures }\end{array}$ \\
\hline \multirow[t]{2}{*}{$\begin{array}{l}\text { Activity } 2 \text { - Group } \\
\text { work }\end{array}$} & Writing skills & Instagram & $\begin{array}{l}\text { Browse pictures generated for Activity } \\
1 \text { 's content on Instagram and choose } \\
\text { one }\end{array}$ \\
\hline & $\begin{array}{l}\text { Grammar } \\
\text { structures }\end{array}$ & $\begin{array}{l}\text { Wikis (via } \\
\text { BlackBoard Learn) }\end{array}$ & $\begin{array}{l}\text { Create a story and post it with their } \\
\text { picture to a Wiki }\end{array}$ \\
\hline \multirow{2}{*}{$\begin{array}{l}\text { Activity } 3 \text { - Group } \\
\text { work }\end{array}$} & Writing skills & Instagram & Take/post a picture to Instagram \\
\hline & $\begin{array}{l}\text { Vocabulary } \\
\text { skills }\end{array}$ & $\begin{array}{l}\text { Wikis (via } \\
\text { BlackBoard Learn) }\end{array}$ & $\begin{array}{l}\text { Create a story and post it with their } \\
\text { picture to a Wiki }\end{array}$ \\
\hline
\end{tabular}




\section{Activity 1: Present about your holiday}

For the first activity, students were asked to choose one of three social media outlets: Twitter, Tumblr, or Instagram, to post a daily photograph of something special about each day of their 10-day mid-semester holiday. Photographs were meant to be used as basis for an in-class speaking activity about their holidays. To make it easier to track these photographs, students were asked to use a unique hashtag that wasn't previously used by others. To avoid any possible cultural conflicts, students were instructed not to show any female faces in their pictures. No further instructions were given.

Upon surveying students before the break, all of them confirmed that they prefer to use Instagram to post their photographs. Accordingly, to encourage students to participate, the teacher created a professional Instagram account to take part in the project and started posting her own daily pictures during the break. The teacher posted instructions for the project to the assigned hashtag to make sure all students are aware of what they needed to do (see Figure 2).

By the end of the holiday, there were 232 posts added to the hashtag. It was noteworthy that there were only 5 English captions in total: "Thanks my classmet\&friend (⿻心,", "I like this name hhhhhhhh $\bullet, "$ "with friends," "Wedding in AJ," and "Let's draw $\square$."

When students came back from the holiday, they were asked to choose five pictures from their own content to prepare for a 2-minute presentation about their break. Presentations were prepared and presented in the same two-hour class. Students who did not post any pictures during the break were asked to explore the hashtag to find pictures they could relate to and use for their presentations. They were required to give credit to the owners of these pictures and to ask permission from

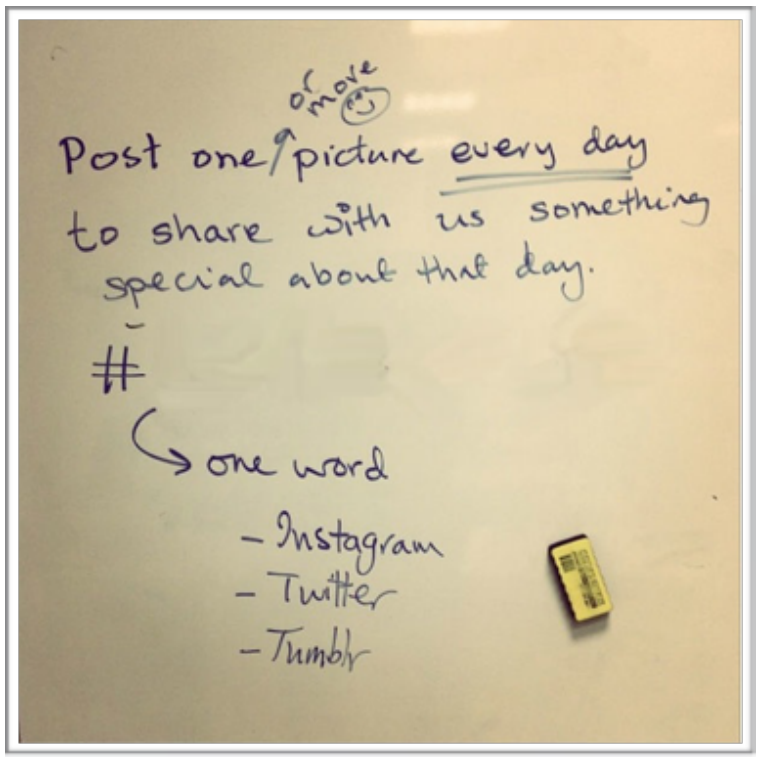

Figure 2: Instructions posted to Instagram. Note that the hashtag was blurred to maintain students' privacy and anonymity. them before using their pictures.

The teacher noted that, unlike previous similar activities, students did not waste a lot of their preparation time trying to look for pictures and relating them to their actual experiences. She also noted that ease of access to pictures that were already filtered using Instagram made students focus on the language used rather on content. When presenting their holiday experience, students felt proud to share pictures they took themselves, and classmates were encouraged to check pictures on Instagram to like them. 


\section{Activity 2: Write a story about a holiday}

Since content generated for Activity 1 and attached to the associated hashtag was contextualized and relevant to students' environment, it was feasible to utilize the same content for an in-class group activity targeting writing and grammar skills. For this activity, students were put in groups of three and asked to explore the hashtag to pick a picture they found inspiring. Using wikis on BlackBoard, learners were asked to write a story about the picture using language structures that had been covered in class (see Figures 3 and 4).

After introducing the activity with these instructions to the first class section, it was noticed that students did not explore the hashtag to see other groups' pictures. Rather, they used their own pictures, and often a picture taken by a socially dominant group member. Having two sections gave the teacher a chance to refine the activity for the second section based on her first implementation. Accordingly, the second section was clearly instructed not to use a picture taken by group members.

The teacher encouraged students to post their stories as comments on pictures they chose. None, however, chose to do so. When asked for the reason behind this reluctance, students explained that posting such comments didn't help their social image, or as a student said: "It's embarrassing. My followers will make fun of me" (own translation). Compared to similar activities completed without Instagram, it was observed that students found it easier to compose their stories because they were able to relate to the places or activities that were captured. Composition wasn't a matter of generating ideas as much as it was about generating language.

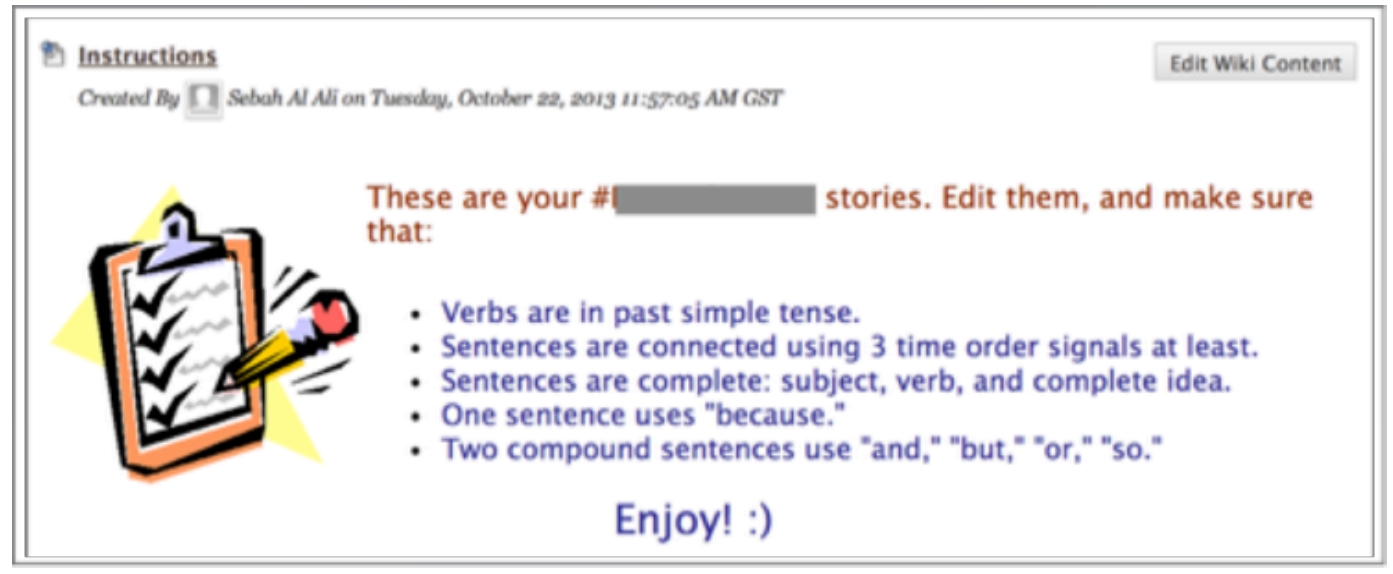

Figure 3: Instructions for the first writing activity using pictures generated for the previous activity. 


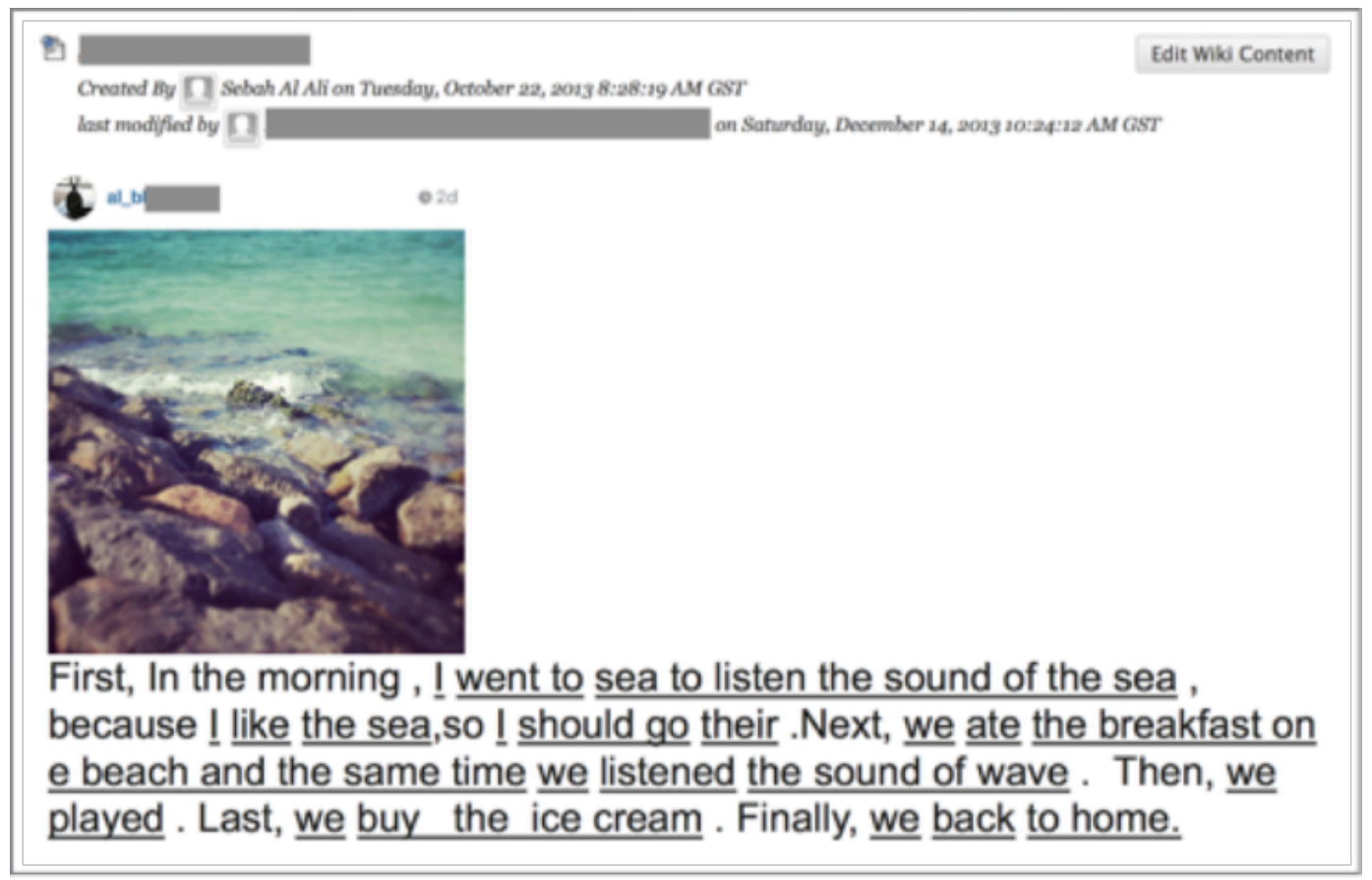

Figure 4: An example of a story created for Writing Activity 1 about a picture taken by a student they don't know from the other section.

\section{Activity 3: Write a story about a student at college}

The third activity was very similar to the second one, with slightly different instructions (see Figure 4). For this activity, students were given the option to take their own pictures from around the college and post them to Instagram with their stories. It was noteworthy that all students in both classes chose to take their own pictures and posted them to Instagram -although they refused to add their stories as captions or comments for the same reasons mentioned above. Both class sections then used wikis to allow students to work in groups on their stories and share them with others (see Figure 5). Since students chose to take their own pictures and because they had the restriction of using words from their vocabulary list for that week, there were some difficulties with generating ideas for their pictures and stories. Giving them the opportunity to go around the college to look for inspiration, however, helped them generate creative ideas.

The teacher noted that students were much more motivated to complete this activity than the previous two activities because they had to take pictures together for it, rather than using older photographs or posts by someone else. They were eager to share their stories with their classmates, and they all made sure their pictures were properly displayed as they read their stories. 


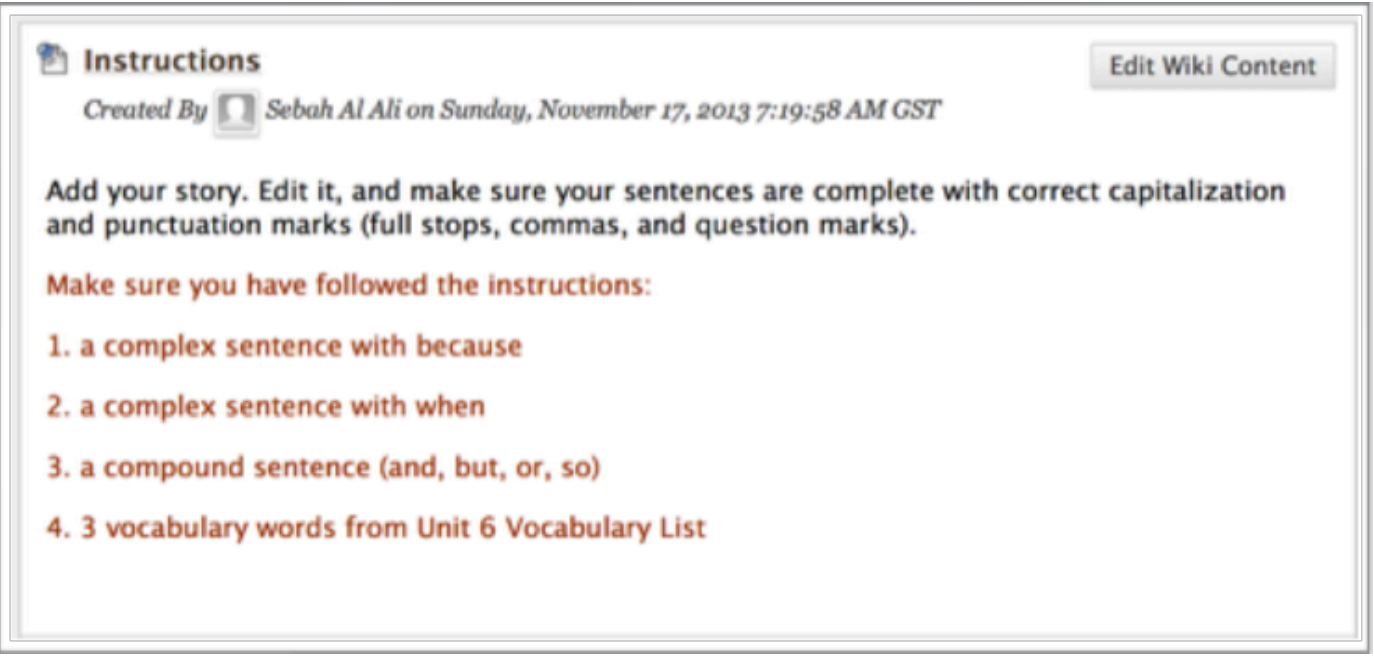

Figure 5: Instructions for the second writing activity.

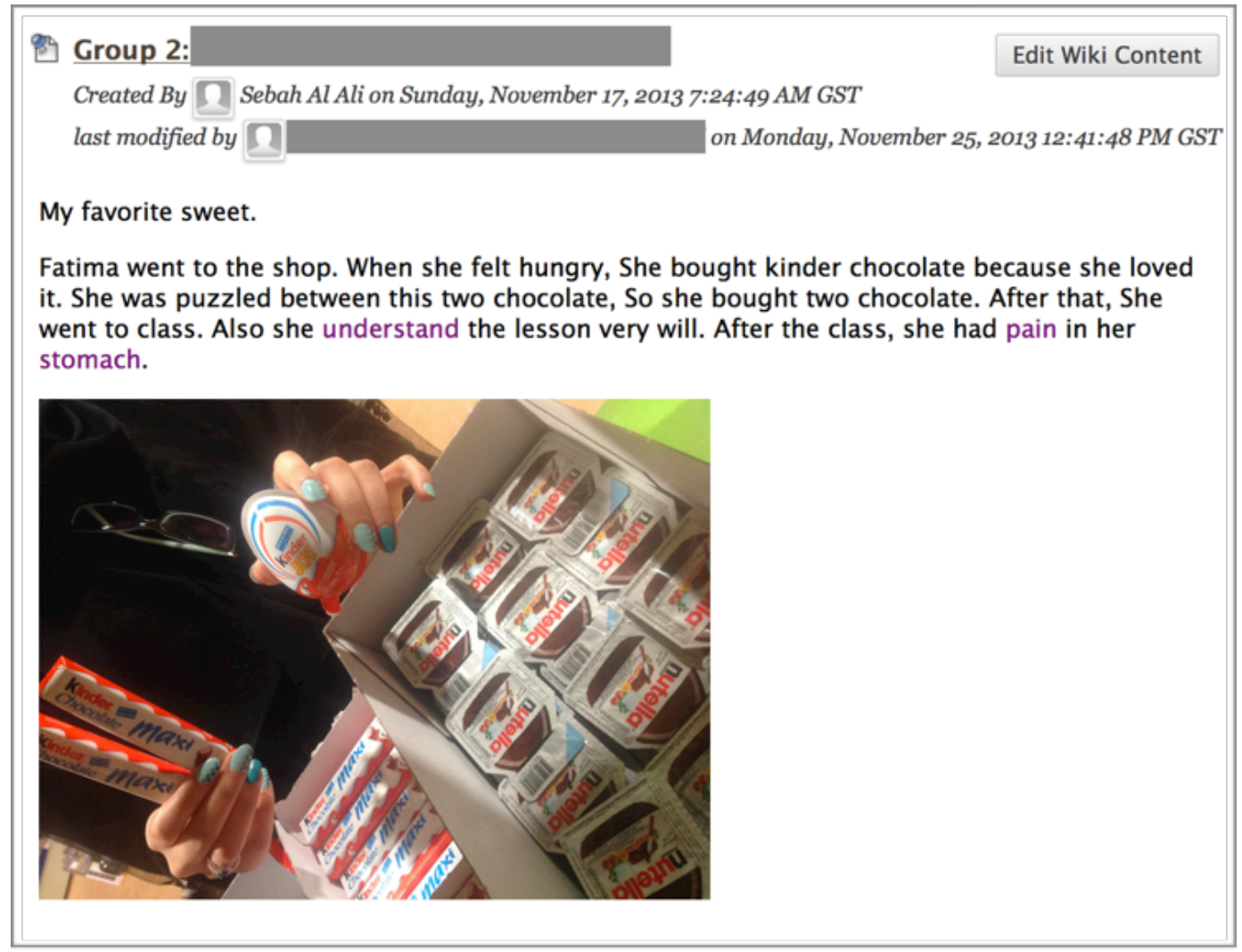

Figure 6: An example of a story created for Activity 3.

\section{Attitudinal Surveys}

Towards the end of the semester, an anonymous e-survey was distributed to students with three yes/no questions and one open-ended question to see their general satisfaction levels with using Instagram as an mLearning tool. Only 16 students completed the survey. As shown in Table 3, students seem to generally like the idea of using Instagram for learning purposes. In their answers to the open-ended question asking for suggestions 
to improve the Instagram experience, only two comments were given, "to get better at using it" and "it was nice to use it" (own translation).

Table 3. Attitudinal survey filled out by students $(n=16)$

Question

Did you like using Instagram for learning purposes in class?

\begin{tabular}{ll} 
Yes & No \\
\hline $16(100 \%)$ & 0 \\
$15(93.75 \%)$ & $1(6.25 \%)$ \\
$14(87.50 \%)$ & $2(12.50 \%)$
\end{tabular}

\section{Implementation Difficulties and Limitations}

Instagram is one the most-used social networking tools at the institution. Feeds are regularly updated and/or checked throughout the day by participants in this study. As Hockly (2013) notes, a redefinition can only be possible if there was "a certain amount of familiarity with mobile devices on the part of teachers and learners" (p.83). Hence, familiarity with the tool was an advantage to this project. Familiarity with the tool from a social aspect, however, did not necessarily transfer to this project -at least at first. During the first few of days of the first activity, the only account posting to the project hashtag was the teacher's. Students later explained that their reluctance to participate at first was attributed to the fact that this was a first of its kind learning activity and they were not sure about the kind of posts they were expected to add or about the kind of limitations associated with this learning task. After the teacher had posted a few photographs herself, however, demonstrating the kind of information she expected to be shared, pictures started flowing.

A difficulty in accessing content was also found due to the fact that many of the students' accounts were private. This meant that only their approved followers could view their posts. Accordingly, to view their content that was generated for activities, the teacher needed to follow all of her students' accounts, which in turn led to the teacher being left with a feed full of irrelevant content that could not be blocked or restricted without unfollowing the students' accounts. And, when students explored the hashtag, they were limited to publicly available pictures because they didn't necessarily follow everyone posting to the hashtag.

Another major implementation difficulty was due to the fact that students were using their own personal accounts. This proved to be a problem because students refused to post academic content (whether as captions or comments). When asked for an explanation, students expressed that doing so is considered embarrassing and seen to have a negative impact on their social presence on Instagram. This kind of limitation made it difficult for the teacher to extend the last two learning activities by encouraging students to post comments on each other's stories to further reinforce the target language skills/structures. Personal accounts also made it difficult for the teacher to keep track of 
students as students used nicknames among themselves, which had no identifying bios to help the teacher identify students.

Limitations were also faced in regards to surveying students' attitudes. The survey was integrated at a final stage of the class to substitute for a focus group. When attempting to form a focus group discussing students' views and attitudes towards using Instagram as a learning tool, the teacher couldn't collect data. Students were mostly silent and only gave yes/no answers to discussion prompts. Accordingly, a short survey was designed and delivered by email (to eliminate face issues) explaining to students that results of the survey would only be used for research purposes. Given that students were not familiar with the concept of online surveys, to encourage their participation in the survey, only four questions were used, 3 yes/no questions and one open-ended question asking for their suggestions/comments. An additional statement asked participants to express their willingness to be interviewed for more information. None accepted.

\section{Discussion}

Evaluating these activities according to the SAMR model, it can be seen that they can be classified within the modification or redefinition stages of SAMR (see Table 4). The second learning activity was modified by Instagram when students were asked to browse for content generated on Instagram rather than produce it themselves; although this task could have been done with a simple Google search or by browsing a magazine, using Instagram modified this activity, allowing students to contextualize the data and delivering familiar content, with which the students could relate.

Table 4. Analysis of learning activities using the SAMR model

\begin{tabular}{|c|c|c|c|}
\hline Activity & Learning Tools & Learning Tasks & $\begin{array}{l}\text { SAMR } \\
\text { classification }\end{array}$ \\
\hline \multirow[t]{2}{*}{ Activity 1} & Instagram & Take/post 10 pictures to Instagram & redefinition \\
\hline & Keynote & Create/present a presentation using 5 pictures & modification \\
\hline \multirow[t]{2}{*}{ Activity 2} & Instagram & $\begin{array}{l}\text { Browse pictures generated for activity 1's content } \\
\text { on Instagram and choose one }\end{array}$ & modification \\
\hline & $\begin{array}{l}\text { Wikis (via BlackBoard } \\
\text { Learn) }\end{array}$ & $\begin{array}{l}\text { Create a story and post it with their picture to a } \\
\text { Wiki }\end{array}$ & modification \\
\hline \multirow[t]{2}{*}{ Activity 3} & Instagram & Take/post a picture to Instagram & redefinition \\
\hline & $\begin{array}{l}\text { Wikis (via BlackBoard } \\
\text { Learn) }\end{array}$ & $\begin{array}{l}\text { Create a story and post it with their picture to a } \\
\text { Wiki }\end{array}$ & modification \\
\hline
\end{tabular}

Utilizing Instagram as a production tool for learning activities 1 and 3 facilitated active learning and redefined these learning activities, as students were responsible for generating their own ideas for their writing tasks and for taking pictures that expressed their ideas clearly; this could not have been done without the Instagram application. Students also felt responsible for generating content and were encouraged to actively 
use it for learning purposes. The use of a unique hashtag for these learning activities also allowed content to be openly shared in different classes and gave students an element of encouragement, as their audience scope was not limited to their classmates.

It can be argued that Instagram helped redefine teaching as well through these activities. Collecting materials to help students generate content was a daunting task for the teacher: content she brought in usually was not suitable for all students, did not reflect what students had to offer, or limited the scope of student activity. Instagram, however, eased the process of providing students with contextualized content they could relate to and use to produce further content that made sense to them. In other words, Instagram helped create a more personalized learning experience for students, which Romrell, Kidder, and Wood (2014) believe to be a vital element of successful mLearning. Students did not complain about a lack of ideas or understanding of the content used to generate language. They felt comfortable with the pictures and familiar with them, and they had a wide range of options to choose from. This helped them refocus their attention and work on producing target language structures properly. Also, given the nature of the project and the plethora of pictures it generated about various topics, students had limitless relevant choices that they could relate to in different ways or with which to associate an incident..

Similarly to what Waycott, Sheard, Thompson, and Clerehan (2013) noted in regards to use of social media in class, using Instagram for a project that is not limited to a single class also helped create a stronger community of learners among students in the same level, but in different sections. Students at the institution where this study took place usually do not interact with students from other sections and do not try to socialize with them. As reported in Gikas and Grant (2013) in reference to social media tools, Instagram created better chances of communication among students. Given that the activities implemented in this experiment were attached to unique hashtags that were used by both sections, Instagram allowed for creating a sense of community, and encouraged students to go outside of their social comfort zone to meet level-mates who chose their pictures for stories. This in turn also created a greater sense of achievement and pride for those students whose pictures were chosen by others. It was also remarkable that although students found it interesting to browse others' posts, their engagement and motivation levels were much higher when they took pictures themselves to suit the activity on hand. In other words, consuming content, even if it was produced by them earlier, was not as motivating as generating content.

\section{Teaching Implications}

Based on the difficulties experienced in implementing the current study, it seems to be easier and more practical to have students create academic Instagram accounts using unique usernames, like their university IDs, to be used for learning purposes. These accounts may solve the problem of students shying away from posting academic content to their social accounts and feeling embarrassed about it. It will also help the teacher 
to enforce guidelines about the kind of content posted to these accounts. Academic accounts will encourage students to keep their accounts open to public, which in turn will make it easier for content to be explored and viewed across sections/classes.

From what was observed in the course of this project, learners did not add captions on their own when they were not required to do so. This could be because they usually do not post captions (whether in their own language or any other language) with most of their other personal pictures. As a result, it may be useful to make it clear to learners that captions are recommended and encouraged. Captions in Instagram do not have a character limit, but line breaks are not possible.

It was also noteworthy that although students were motivated to explore content on Instagram or use their own previously posted pictures, they were much more involved and motivated when a learning task required them to post a new picture they had taken specifically for that task. It engendered a sense of competition to see who could be the most creative and artistic with their pictures, and it encouraged them to produce creative content rather than doing the bare minimum to complete an activity.

\section{Conclusion}

Due to its popularity among students, Instagram was utilized as an mLearning tool to generate content that was used for one speaking activity, and two writing activities reinforcing speaking, grammar, writing and vocabulary skills. Using Instagram helped redefine the language classroom as it allowed students to generate ideas for their writing activities with contextually-relevant content and offered them a learning experience that they enjoyed. A few teaching recommendations were concluded from this project to ensure a better integration of Instagram as a learning tool in language classrooms.

\section{Acknowledgements}

Special thanks to Robert Miles for his support and feedback that helped shape this study, and to Noor Al-Ali for her help in reviewing the paper. 


\section{References}

Bell, M. A. (2013). Picture this! Using Instagram with students. Internet@Schools, 20(4), pp. 23-25.

Bowman, N. D., \& Akcaoglu, M. (2014). "I see smart people!": Using Facebook to Supplement Cognitive and Affective Learning in the University Mass Lecture. The Internet and Higher Education, 23, pp. 1-8.

Boyd, D. (2014). It's complicated: The social lives of networked teens. London, UK: Yale University Press.

Cavanaugh, C., Hargis, J., Kamali, T., \& Soto, M. (2013). Substitution to augmentation: Faculty adoption of iPad mobile learning in higher education. Interactive Technology and Smart Education, 10(4), pp. 270-284.

Chell, G. \& Dowling, S. (2013). Substitution to redefinition: The challenges of using technology. In Dowling, S., Gunn, C., Raven, J. and Hayhoe, S. (Eds.), eLearning in action: Redefining learning. Abu Dhabi. HCT Press.

Counts, S., \& Fisher, K. E. (2010). Mobile social networking as information ground: A case study. Library \& Information Science Research, 32(2), pp. 98-115.

Dunn, L. (2013). Teaching in higher education: can social media enhance the learning experience? In 6th Annual University of Glasgow Learning and Teaching Conference, 19th Apr 2013, Glasgow, UK.

Global Digital Statistics 2014. (2014, January 8). Retrieved July 6, 2014, from http:// etonpreneurs.com/uploads/Global\%20Social,\%20Digital\%20\&\%20Mobile\%20 Statistics,\%20Jan\%202014.pdf

Gikas, J., \& Grant, M. M. (2013). Mobile computing devices in higher education: Student perspectives on learning with cellphones, smartphones \& social media. The Internet and Higher Education, 19, pp. 18-26.

Hockly, N. (2012). Substitute or redefine?. Modern English Teacher, 21(3), pp. 40-42.

Hockly, N. (2013). Mobile learning. ELT Journal, 67(1), pp. 80-84.

Hrastinski, S., \& Dennen, V. (2012). Social media in higher education: Introduction to the special issue. The Internet and Higher Education, 15(1), pp. 1-2.

Krüger-Ross, M., Waters, R. D., \& Farewell, T. M. (2012). Everyone's all a-twitter about twitter. In K. K. Seo (Ed), Using social media effectively in the classroom (pp. 117- 131). New York, NY: Routledge. 
Lunden, I. (2014, January 21). Instagram Is The Fastest-Growing Social Site Globally, Mobile Devices Rule Over PCs For Access. TechCrunch. Retrieved July 6, 2014, from http://techcrunch.com/2014/01/21/instagram-is-the-fastest-growingsocial-site-globally-mobile-devices-rule-over-pcs-for-social-access/

Mao, J. (2014). Social media for learning: A mixed methods study on high school students' technology affordances and perspectives. Computers in Human Behavior, 33, pp. 213-223.

McBride, K. (2009). Social-networking sites in foreign language classes: Opportunities for re-creation. The next generation: Social networking and online collaboration in foreign language learning, pp. 35-58.

McCarthy, J. (2010). Blended learning environments: Using social networking sites to enhance the first year experience. Australasian Journal of Educational Technology, 26(6), 729-740.

Oliveira, M. (2014, May 15). Canadians' social media use plateauing, mobile usage surging: Poll. The Canadian Press.

Puentedura, R. (2009) 'Transformation, technology, and education', Retrieved July 6, 2014, from http://hippasus.com/resources/tte/puentedura tte.pdf

Press Page. (n.d.). Instagram. Retrieved July 6, 2014, from http://instagram.com/press/

Reed, P. (2013). Hashtags and retweets: using Twitter to aid Community, Communication and Casual (informal) learning. Research in Learning Technology, 21. Retrieved from http://www.researchinlearningtechnology.net/ index.php/rlt/article/view/19692

Roblyer, M. D., McDaniel, M., Webb, M., Herman, J., \& Witty, J. V. (2010). Findings on Facebook in higher education: A comparison of college faculty and student uses and perceptions of social networking sites. The Internet and Higher Education, 13(3), pp. 134-140.

Romrell, D., Kidder, L., \& Wood, E. (2014). The SAMR Model as a Framework for Evaluating mLearning. Online Learning - Formerly The Journal Of Asynchronous Learning Networks, 18(2). Retrieved from http://olj.onlinelearningconsortium.org/ index.php/jaln/article/view/435

Salomon, D. (2013). Moving on from Facebook Using Instagram to connect with undergraduates and engage in teaching and learning. College \& Research Libraries News, 74(8), pp. 408-412. 
eaman, J., \& Tinti-Kane, H. (2013). Social media for teaching and learning. Babson Survey Research Group.

Tekulve, N., \& Kelly, K. (2013). Worth 1,000 words: Using Instagram to engage library users. Brick and Click Libraries Symposium. Retrieved July 25, 2015 http:// ecommons. udayton.edu/roesch_fac/20

Vie, S. (2008). Digital divide 2.0:"Generation M" and online social networking sites in the composition classroom. Computers and Composition, 25(1), pp. 9-23.

Warren, S. J., \& Wakefield, J. S. (2012). Learning and teaching as communicative actions: Social media as educational tool. In K. K. Seo (Ed), Using social media effectively in the classroom (pp. 98- 113). New York, NY: Routledge.

Waycott, J., Sheard, J., Thompson, C., \& Clerehan, R. (2013). Making students' work visible on the social web: A blessing or a curse?. Computers \& Education, 68, pp. 86-95. 